\title{
AN EPIDEMIOLOGICAL STUDY OF TUBERCULOSIS IN FOOTHILLS OF UTTARAKHAND.
}

Amit Jha, Sanjay Kumar Nigam, Nilam Nigam

1. Assistant Professor, Department of Community Medicine, Rama Medical College Hospital \& Research Centre, Mandhana, Kanpur, Uttar Pradesh.

2. Professor, Department of Pathology, Rama Medical College Hospital \& Research Centre, Mandhana, Kanpur, Uttar Pradesh.

3. Associate Professor, Department of Pharmacology, Rama Medical College Hospital \& Research Centre, Mandhana, Kanpur, Uttar Pradesh.

\section{CORRESPONDING AUTHOR}

Dr. Sanjay Kumar Nigam,

House No. 308,

Rama Medical College, Mandhana,

Kanpur, Uttar Pradesh-209217,

E-mail: sknigam@yahoo.com,

Ph: 00919411918206.

ABSTRACT: INTRODUCTION: The international tuberculosis situation is complicated by the growing impression that tuberculosis is no longer a major public health problem'. Zaki MH in 1968 had short listed the following factors: chronicity, ability of bacilli to stay alive in body for years, increase in life expectancy, high level of endemicity in ethnic groups even in the midst of affluence in the western world, the frequent occurrences of isolated epidemics in certain parts of the world and the emergence of MDRTB. The 1990 World Health Organization (WHO) report on the Global Burden of Disease ranked TB as the seventh most morbidity-causing disease in the world and expected it to continue in the same position up to 2020 [2]. MATERIAL \& METHODS: The present study was conducted among all the families registered with the Rural \& Urban Health Training Centers (RHTC \& UHTC) under the jurisdiction of Field practice areas of the Department of Community Medicine, Himalayan Institute of Medical Sciences, Dehradun, Uttrakhand. It was Community based survey, Cross -sectional (Observational) study. Entire study population (10 years \& above) with $100 \%$ enumeration (census) of households. House to house survey was conducted on all the families registered with the Rural \& Urban Health Training Centers (RHTC \& UHTC) under the jurisdiction of Field practice areas of the Department of Community Medicine, Himalayan Institute of Medical Sciences, and sociodemographic profile of each house-hold was recorded. RESULTS: It can be observed from the table that a total of $399(1.68 \%)$ symptomatic were screened out of a total study population of 23,618 from 10 different peri-urban field practice locations; $73(0.30 \%)$ symptomatics turned out to be cases of Tuberculosis confirmed either as sputum positive cases by Microscopy or by other criteria. It is evident that overall (mean) prevalence of the disease was 3.09 per 1000 study population; notably, the prevalence was as high as $16.17 / 1000$ population at Khatta \& Dorbassi followed by 13.04/1000 population at Doiwala. Age -wise distribution of Pulmonary Tuberculosis and statistical association of its prevalence with age. It can be observed from the above table that prevalence of Pulmonary Tuberculosis was found to be directly proportional to client's advancing age. Highest prevalence i.e 14.79/ 1000 was in 70 years \& above age group, followed by $9.52 / 1000$ in the age group of $60-70$ years, 5.92/1000 in the age group of 40-50 tears and 5.82/1000 in the age group of 50-60 years; the least prevalence i.e 1.48 / 1000 was found in the age group of 10- 20 years. This difference in prevalence of pulmonary tuberculosis 
in terms of age group was statistically significant. CONCLUSION: We conclude that present day epidemiology of tuberculosis in India have not yet been fully elucidated, a considerable amount of information, of varying degrees of reliability and accuracy, has accumulated during the course of the last 30 or 40 years enabling us to see at least the outlines of the problem and furnishing the basis for future action.

KEYWORDS: Pulmonary Tuberculosis, prevalence, Uttarakhand, sociodemography.

INTRODUCTION: The international tuberculosis situation is complicated by the growing impression that tuberculosis is no longer a major public health problem'. Zaki MH in 1968 had short listed the following factors: chronicity, ability of bacilli to stay alive in body for years, increase in life expectancy, high level of endemicity in ethnic groups even in the midst of affluence in the western world, the frequent occurrences of isolated epidemics in certain parts of the world and the emergence of MDRTB. The 1990 World Health Organization (WHO) report on the Global Burden of Disease ranked TB as the seventh most morbidity-causing disease in the world and expected it to continue in the same position up to 2020 [2]. That the Tuberculosis situation in an area, community or country is the product of the 'Disease Triangle' comprising bacillus, host and environment is universally accepted. It is equally well established that these factors vary considerably from one country to another and from area to area in a country [10] .Unlike western countries, where a more or less efficient notification system has existed for a long time, India has been lacking in even approximate data about the prevalence and incidence of tuberculosis infection and disease as well as mortality rates. Although the relevant facts regarding the present day epidemiology of tuberculosis in India have not yet been fully elucidated a considerable amount of information, of varying degrees of reliability and accuracy, has accumulated during the course of the last 30 or 40 years enabling us to see at least the outlines of the problem and furnishing the basis for future action [11]. India is classified along with the sub-Saharan African countries to be among those with a high burden and the least prospects of a favorable time trend of the disease. The average prevalence of all forms of tuberculosis in India is estimated to be 5.05 per thousand, prevalence of smear positive cases 2.27 per thousand and average annual incidence of smear positive cases at 84 per 100,000 annually [9] .The available circumstantial evidence in India points towards a long history of many tuberculosis epidemics; tuberculosis was, is and may remain a dilemma in the future [12]. The national ARTI was estimated at $1.5 \%$ i.e. 75 new smear positive pulmonary TB cases are expected per 100,000 population annually [13]. Significantly, with atypical parameters like geotopographical / disadvantaged population living in periurban habitat/slums having varying socio-epidemiological predictors, the study of epidemiology of pulmonary tuberculosis is most likely to provide new insight. In view of rapidly changing and evolving evidence base in terms of epidemiological parameters and determinants of Pulmonary Tuberculosis in various settings, the present study has been designed to elicit and validate presumed epidemiological correlates and variables affecting Pulmonary Tuberculosis among field practice areas population of HIMS.

AIMS AND OBJECTIVES: To find out the prevalence of pulmonary tuberculosis among population aged 10 years and above. To determine the various socio-epidemiological correlates of pulmonary tuberculosis.

MATERIAL \& METHODS: Study Population: All persons 10 years of age \& above (17,952 ) belonging to the families registered with the Rural \& Urban Health Training Centres under the 
jurisdiction of Field Practice areas of the Department of Community Medicine, HIMS, Dehradun were included as study population.

TYPE OF STUDY: Community based survey, Cross -sectional (Observational) study.

STUDY AREA: Universe of the Study comprised all the families registered with the Rural \& Urban Health Training Centers under the jurisdiction of Field practice areas of the Department of Community Medicine, Himalayan Institute of Medical Sciences, and HIHT. Out of a total population of 23,618, population from across the catchments of Rural Health Training Centre (RHTC) i.e Rajeev Nagar, Teliwala, Khatta \& Dor Bassi, Dharmuchak, Kurkawala, Keshavpuri, Gesharpuri \& Doiwala was12,588. Rest of the universe of the study was made up by a population of 11,030 from the catchments of Urban Health Training Centre (UHTC) i.e Chandreshwar Nagar and Shisamjhari, Rishikesh

DURATION OF STUDY: The period of the study was one (01) Year beginning from 19.05.2008 to 20.05 .2009

SAMPLE SIZE: Entire study population (10 years \& above) with $100 \%$ enumeration (census) of households.

METHODOLOGY: House to house survey was conducted on all the families registered with the Rural \& Urban Health Training Centers (RHTC \& UHTC) under the jurisdiction of Field practice areas of the Department of Community Medicine, Himalayan Institute of Medical Sciences, HIHT and socio-demographic profile of each house-hold was recorded.

All members 10 years of age and above from the surveyed house-holds having either history and or presenting complaints of cough for three weeks or more in duration and those already diagnosed cases of Pulmonary Tuberculosis included either as 'defaults', 'relapsed' 'failure', 'not completed treatment' or 'chronic' cases and undergoing treatment either from any Category of DOTS or non-DOTS regimen, were interviewed by administering a predesigned, pre-tested and structured instrument.

Clients having cough for duration of 3 weeks or more and or having associated symptoms suggestive of pulmonary Tuberculosis and also those already diagnosed as cases of Pulmonary Tuberculosis undergoing treatment were identified as study subjects.

All data related to socio-demography, key practices / behaviors, environment, disease / morbidity profile including family history of the disease under study and history of present / past treatment of the study subjects were elicited and recorded.

A detailed clinical assessment of the study subjects was then carried out including general and systemic examination with particular reference to Respiratory system.

All newly detected symptomatics were subjected to sputum microscopy as per standard RNTCP Protocol.

Sputum was collected at RHTC \& UHTC and sputum specimen sent to Department of Microbiology, HIMS for Direct Microscopy for AFB.

INCLUSION CRITERIA: All persons from among those 10 years of age and above, belonging to the families registered with the Rural \& Urban Health Training Centers, under the jurisdiction of Field Practice areas of the Department of Community Medicine, HIMS, Dehradun

Having history and or presenting complaints of cough for three weeks or more in duration and 
Already diagnosed cases of Pulmonary Tuberculosis included either as 'defaults', 'relapsed' 'failure', 'not completed treatment' or 'chronic' cases and undergoing treatment either from any Category of DOTS or non-DOTS regimen , comprised the study subjects.

EXCLUSION CRITERIA: Those patients who were cured or had already completed their treatment regimen with negative smears at the end of the treatment by either DOTS or nonDOTS regimen were excluded from the study.

A CASE OF PULMONARY TUBERCULOSIS: For the study purpose a case of pulmonary tuberculosis was defined as one who had at least two initial sputum smear examinations (direct smear microscopy) positive for AFB or a person with one sputum smear examination positive for AFB and radiographic abnormalities consistent with active pulmonary T.B. as determined by treating Medical Officer(MO) or TB in a patients with one sputum smear specimen positive for AFB and culture positive for M. tuberculosis or TB in a patient with symptoms suggestive of TB with at least three sputum smear examinations negative for AFB and radiographic abnormalities consistent with active pulmonary TB as determined by the treating MO followed by a decision to treat the patient with a full course of anti-tuberculosis therapy or diagnosis based on positive culture but negative AFB sputum smear examination [13].

RESULTS AND DISCUSSION: Area wise population of the Universe of the Study which comprised the field practice areas of the department of community medicine, Himalayan Institute of Medical Sciences, HIHT.

Out of a total population of 23,618, population from across the catchments of Rural Health Training Centre (RHTC) i.e Rajeev Nagar, Teliwala, Khatta \& Dor Bassi, Dharmuchak,

Kurkawala, Keshavpuri, Gesharpuri \& Doiwala was12588 (53.30\%).

Rest of the universe of the study was made up by a population of 11,030(46.70\%) from the catchments of Urban Health Training Centre (UHTC) i.e Chandreshwar Nagar and Shisamjhari, Rishikesh

It can be observed from the table that highest proportion of study subjects i.e. $183(45.88 \%)$ ) belonged to families with family size 3-5 followed by $137(34.33 \%)$ from families with size 6-8. Table 1.3 shows distribution of study subjects according to type of family they belonged. The families of most of the subjects and as many as $270(67.7 \%)$ were of unitary type followed by 129 (32.3\%) joint families. The above table (1.4) also shows distribution of study subjects' families according to socio economic status as per modified B.G. Prasad's classification; most of the families with as many as $155(38.8 \%)$ belonged either to lower middle class or $139(34.8 \%)$ to upper lower class.

Table 2.1 gives distribution of the study subjects according to the local environment they live in. It can be seen from the table that study subjects' immediate vicinity had undesirable environmental contaminant/pollutant elements with 184 (46.1\%) and 144(36.1\%) of them living in a local environment of dust and smoke respectively. Table 2.2 shows distribution of study subjects by presence or absence of air pollution. Though any source of air pollution was not observed/reported by the most i.e. as many as $280(70.2 \%)$ of the subjects, $119(29.8 \%)$ of them nevertheless had a source of air pollution in the immediate environment. As regards distribution of study subjects' families by intensity of vehicular traffic as an environmental characteristic, most of the respondents i.e. 264 (62.2\%) reported minimal vehicular traffic as against $133(33.3 \%)$ reporting moderate vehicular traffic. Table 2.4 gives profile of study 
subject's handlings type of dust. Most of the respondents i.e. 244 (61.2\%) reported handling house dust with insignificant proportions giving history of handling other kinds of dust. Distribution of respondents in terms of type of housing is presented at table 2.5. It can be observed that significant proportion of study subjects i.e. $233(57.6 \%)$ lived in pucca houses followed by 123 (30.8\%) living in semi pucca houses; only 46 (11.5\%) respondents lived in Kutcha houses. Table 2.6 \& 2.7 relate study subjects with overcrowding and ventilation. As many as 261 (65.4\%) and 290 (72.7\%) respondent subjects lived in overcrowded and inadequately ventilated houses respectively.

Table 3.1 shows profile of study subjects in terms of choice of type of diet. Significant proportion i.e. $270(67.7 \%)$ of respondents were non-vegetarian as against $129(32.3 \%)$ vegetarians. As regards respondents' status of nutrition, it can be seen from table 3.2 that highest proportion of them i.e. 280(70.2\%) were well-nourished. Table 3.3 shows distribution of respondent study subjects by behavior towards addiction particularly smoking habit. Significant proportion of the respondents i.e. 258(64.7\%) were non-smokers as against 141(35.3\%) smokers. Distribution of study subjects according to history of risk behaviors/ risk situations (table 3.4) reveals that a very insignificant proportion of respondents i.e 15(3.8\%) had such history.

Table 4 shows area wise distribution of symptomatics and confirmed cases of Tuberculosis and its period prevalence. It can be observed from the table that a total of $399(1.68 \%)$ symptomatic were screened out of a total study population of 23,618 from 10 different peri-urban field practice locations; $73(0.30 \%)$ symptomatics turned out to be cases of Tuberculosis confirmed either as sputum positive cases by Microscopy or by other criteria. It is evident that overall (mean) prevalence of the disease was 3.09 per 1000 study population; notably, the prevalence was as high as $16.17 / 1000$ population at Khatta \& Dorbassi followed by 13.04/1000 population at Doiwala.

Table 5 reveals the number of confirmed cases of pulmonary tuberculosis among the symptomatic according to findings by sputum microscopy. It can be seen from the table that 52 $(71.24 \%)$ were sputum smear positive cases as against $21(28.76 \%)$ of the cases being sputum negative.

CONCLUSION: We conclude that present day epidemiology of tuberculosis in India have not yet been fully elucidated, a considerable amount of information, of varying degrees of reliability and accuracy, has accumulated during the course of the last 30 or 40 years enabling us to see at least the outlines of the problem and furnishing the basis for future action [11]. Significantly, with atypical parameters like geo-topographical /disadvantaged population living in rural or periurban habitat/slums having varying socio-epidemiological predictors, the study of epidemiology of pulmonary tuberculosis is most likely to provide new insight. In view of rapidly changing and evolving evidence base in terms of epidemiological parameters and determinants of Pulmonary Tuberculosis in various settings, the present study has been designed to elicit and validate presumed epidemiological correlates and variables affecting Pulmonary Tuberculosis among field practice areas of population of HIMS.

\section{BIBLIOGRAPHY:}

1. Zaki MH. On the Epidemiology of Tuberculosis in some selected countries: highlights \& Prospects for control and eradication, Part 1. Am Public Health 1988; 58: 1692-712. 
2. Dye C, Scheele S, Dolin P, Pathania V, Raviglione NC. Global burden of tuberculosis: estimated incidence, prevalence and mortality by country. WHO general surveillance and monitoring project. AMA 1999; 282: 677- 86.

3. World health organization. Global tuberculosis control WHO report Geneva, Switzerland. 2004; 331.

4. Narain JP (ed): Tuberculosis - epidemiology and control. World Health organization, Regional office for South East. New Delhi, India, 2002; SEA/TB/2002. 248:15,18.

5. Dipanjan Roy, L.S Chouhan. Epidemiology of Tuberculosis. Ind J Tuberclosis 1994; XXIX: No.3.

6. Braun MM, Badi N, Ryder RW, Baende E, Mukadi Y, Vami NS. A retrospective short study of the risk of tuberculosis among women of child bearing age with HIV Injection in Zaire. AM Rev Respire Dis 1991; 143: 501- 4.

7. Narain JP, Raviglione MC, Kochi A. HIV associated tuberculosis in developing countries: epidemiology and striates for prevention. Tubercle Lung Dis 1992; 73: 311-21.

8. William B. Estimating the import of the epidemic of HIV on tuberculosis in India; as quoted by chakra borty AK, in, Expansion of the tuberculosis program in India: The policy evolution towards decentralization and integration, Feb. 2003. Central for Health research and development, Pune pp. 1-66.

9. Chakraborty AK. Epidemiology of tuberculosis: current status in India. Indian J Med Res 2004; 120: 248-76.

10. The Indian journal of tuberculosis editorial, April 1999, vol. 46.

11. Gothi GD. Epidemiology of tuberculosis in India: review article. India J Tub vol. XXIX, No.3.

12. Nagpal DR. Tuberculosis in India - A perspective. J Indian Med Ass 1978; 71: 44. TB India 2009, RNTCP stats report world health organization; Global tuberculosis control: surveillance, planning, financing: WHO report 2008 Geneva: world health organization (WHO/HTM/TB /2008.393).

13. Minutes of the expert committee. meating to Estimate P.B Burden in India . March 2005. Disectorate of health and family welfare, central TB Divisions, Government of india ,2005. 
Table 1. Distribution of Study Subjects by Religion, Family size, Type of Family and Socio Economic Status ( $n=399)$

\begin{tabular}{|c|c|c|}
\hline Family Characteristics & No. of Families & Percentage \\
\hline \multicolumn{3}{|l|}{ 1.1 Religion } \\
\hline Hindu & 270 & 67.7 \\
\hline Muslim & 125 & 31.3 \\
\hline Christian & 4 & 1 \\
\hline Sikh & 0 & 0 \\
\hline \multicolumn{3}{|l|}{ 1.2 Family size } \\
\hline $1-2$ & 20 & 5.01 \\
\hline $3-5$ & 183 & 45.88 \\
\hline $6-8$ & 137 & 34.33 \\
\hline$>8$ & 59 & 14.78 \\
\hline \multicolumn{3}{|l|}{ 1.3 Type of Family } \\
\hline Unitary & 270 & 67.7 \\
\hline Joint & 129 & 32.3 \\
\hline $\begin{array}{l}\text { 1.4 Socio Economic Status } \\
\text { Upper }\end{array}$ & & \\
\hline Upper Middle & 5 & 1.3 \\
\hline Lower Middle & 31 & 7.8 \\
\hline Upper Lower & 155 & 38.8 \\
\hline Lower & 139 & 34.8 \\
\hline & 69 & 17.3 \\
\hline
\end{tabular}


Table 2 Distribution of Study Subject by Family characteristics i.e. Local Environment, Source of Air Pollution, Vehicular Traffic, Type of Dust, Type of Housing, Overcrowding, Ventilation,

\begin{tabular}{|c|c|c|}
\hline Family Characteristics & No. of Families & Percentage \\
\hline $\begin{array}{l}\text { 2.1 Local Environment } \\
\text { Smoke } \\
\text { Dust } \\
\text { Fumes } \\
\text { (Others) }\end{array}$ & $\begin{array}{c}144 \\
184 \\
17 \\
54\end{array}$ & $\begin{array}{c}36.1 \\
46.1 \\
4.3 \\
13.5\end{array}$ \\
\hline $\begin{array}{l}\text { 2.2 Source of Air Pollution } \\
\text { Present } \\
\text { Absent }\end{array}$ & $\begin{array}{l}119 \\
280\end{array}$ & $\begin{array}{l}29.8 \\
70.2\end{array}$ \\
\hline $\begin{array}{l}\text { 2.3 Vehicular Traffic } \\
\text { Minimal } \\
\text { Moderate } \\
\text { Heavy }\end{array}$ & $\begin{array}{c}264 \\
133 \\
2\end{array}$ & $\begin{array}{c}66.2 \\
33.3 \\
0.5\end{array}$ \\
\hline $\begin{array}{l}\text { 2.4 Type of Dust } \\
\text { House Dust } \\
\text { Wheat Dust } \\
\text { Coal Dust } \\
\text { Cotton Dust } \\
\text { Dye / Chemical } \\
\text { Cattle } \\
\text { Others }\end{array}$ & $\begin{array}{c}244 \\
44 \\
11 \\
4 \\
21 \\
18 \\
57\end{array}$ & $\begin{array}{c}61.1 \\
11.0 \\
2.8 \\
1.0 \\
5.3 \\
4.5 \\
14.3\end{array}$ \\
\hline $\begin{array}{l}\text { 2.5 Type of Housing } \\
\text { Pucca } \\
\text { Kutcha } \\
\text { Semi Pucca }\end{array}$ & $\begin{array}{c}230 \\
46 \\
123\end{array}$ & $\begin{array}{l}57.6 \\
11.6 \\
30.8\end{array}$ \\
\hline $\begin{array}{l}\text { 2.6 Overcrowding } \\
\text { Present } \\
\text { Absent }\end{array}$ & $\begin{array}{l}261 \\
138\end{array}$ & $\begin{array}{l}65.4 \\
34.6\end{array}$ \\
\hline $\begin{array}{l}\text { 2.7 Ventilation } \\
\text { Adequate } \\
\text { Inadequate }\end{array}$ & $\begin{array}{l}109 \\
290\end{array}$ & $\begin{array}{l}27.3 \\
72.7\end{array}$ \\
\hline
\end{tabular}


Table 3 Distribution of Study Subjects by Type of Diet, Status of Nutrition, Addiction (Smoking Habit), Risk Behaviors / Risk Situations

\begin{tabular}{|l|c|c|}
\hline \multicolumn{1}{|c|}{ Respondent Characteristics } & No. of Respondents & Percentage \\
\hline 3.1 Type of Diet & 129 & 32.3 \\
Vegetarian & 270 & 67.7 \\
Non Vegetarian & & \\
\hline 3.2 Status of Nutrition & 280 & 70.2 \\
Well Nourished & 109 & 27.3 \\
Under Nourished & 10 & 2.5 \\
Over Nourished & & \\
& & 35.3 \\
\hline 3.3 Addiction (Smoking Habit) & 141 & 64.7 \\
Smokers & 258 & \\
Non Smokers & & 3.8 \\
& & 96.2 \\
\hline 3.4 Risk Behaviors / Risk Situations & 384 & \\
History Present & & \\
History Absent & & \\
& & \\
\hline
\end{tabular}

Table 4 Area wise Distribution of Symptomatic \& Confirmed cases of Pulmonary Tuberculosis diagnosed by either microscopy or criteria other than microscopy $(n=$ 399)

\begin{tabular}{|c|c|c|c|c|c|}
\hline S.N & Area & $\begin{array}{c}\text { Population } \\
\text { Screened }\end{array}$ & $\begin{array}{c}\text { No. of } \\
\text { Symptomatic }\end{array}$ & $\begin{array}{c}\text { Confirmed } \\
\text { Cases [Old \& } \\
\text { New] }\end{array}$ & $\begin{array}{l}\text { Prevalence } \\
\text { [Per 1000] }\end{array}$ \\
\hline 1 & $\begin{array}{l}\text { Chandreshwar } \\
\text { Nagar }\end{array}$ & 7000 & $\begin{array}{c}68 \\
(0.97)\end{array}$ & $\begin{array}{c}14 \\
(0.20)\end{array}$ & 2.00 \\
\hline 2 & Shisamjhari & 4030 & $\begin{array}{c}113 \\
(2.8)\end{array}$ & $\begin{array}{c}23 \\
(0.57)\end{array}$ & 5.70 \\
\hline 3 & RajeevNagar & 639 & $\begin{array}{c}8 \\
(1.25)\end{array}$ & $\begin{array}{c}1 \\
(0.15)\end{array}$ & 1.56 \\
\hline 4 & Teliwala & 3500 & $\begin{array}{c}78 \\
(2.22)\end{array}$ & $\begin{array}{c}12 \\
(0.34)\end{array}$ & 3.42 \\
\hline 5 & Khatta\&Dorbassi & 680 & $\begin{array}{c}46 \\
(6.76)\end{array}$ & $\begin{array}{c}11 \\
(1.61)\end{array}$ & 16.17 \\
\hline 6 & Dharmuchak & 1378 & $\begin{array}{c}14 \\
(1.01)\end{array}$ & $\begin{array}{c}0 \\
(0)\end{array}$ & 0 \\
\hline
\end{tabular}




\section{ORIGINAL ARTICLE}

\begin{tabular}{|c|l|c|c|c|c|}
\hline 7 & Kurkawala & 2810 & $\begin{array}{c}17 \\
(0.60)\end{array}$ & $\begin{array}{c}0 \\
(0)\end{array}$ & 0 \\
\hline 8 & Keshavpuri & 2850 & $\begin{array}{c}22 \\
(0.77)\end{array}$ & $\begin{array}{c}5 \\
(0.17)\end{array}$ & 1.75 \\
\hline 9 & Gesharpari & 271 & $\begin{array}{c}1 \\
(0.36)\end{array}$ & $\begin{array}{c}1 \\
(0.36)\end{array}$ & 3.69 \\
\hline 10 & Doiwala & 460 & $\begin{array}{c}32 \\
(6.95)\end{array}$ & $\begin{array}{c}6 \\
(1.30)\end{array}$ & 13.04 \\
\hline & Total & 23,618 & 399 & 73 & 3.09 \\
& & $(1.68)$ & $(0.30)$ & \\
\hline
\end{tabular}

Table 5 Distribution of confirmed cases of Pulmonary Tuberculosis by Microscopy for Sputum Positivity for Acid Fast Bacilli $(n=73)$

\begin{tabular}{|l|c|c|}
\hline \multicolumn{1}{|c|}{ Diagnostic Status by Microscopy } & Confirmed Cases & Percentage \\
\hline Sputum smear positive Cases & 52 & 71.24 \\
\hline Sputum Smear Negative Cases & 21 & 28.76 \\
\hline
\end{tabular}

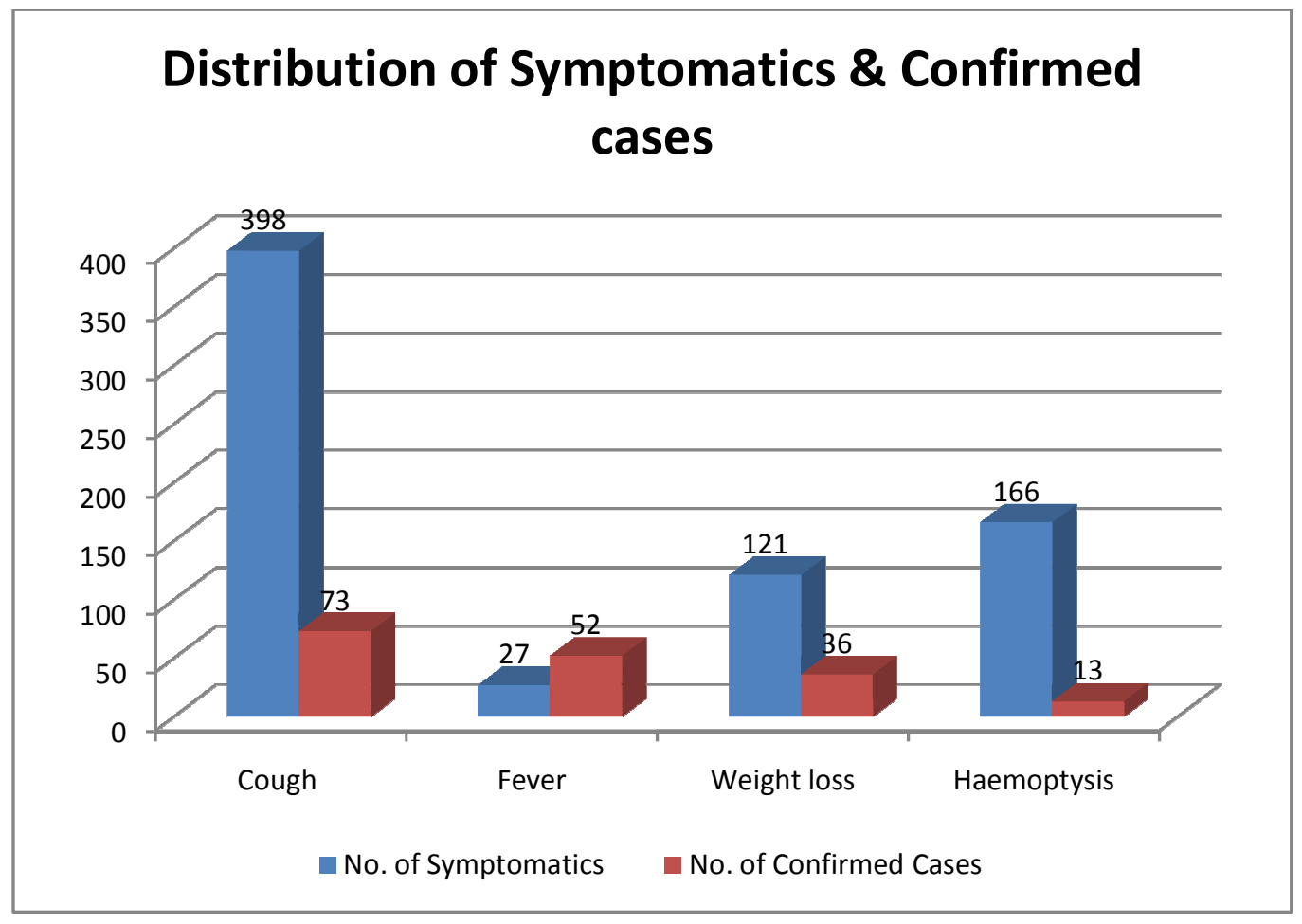




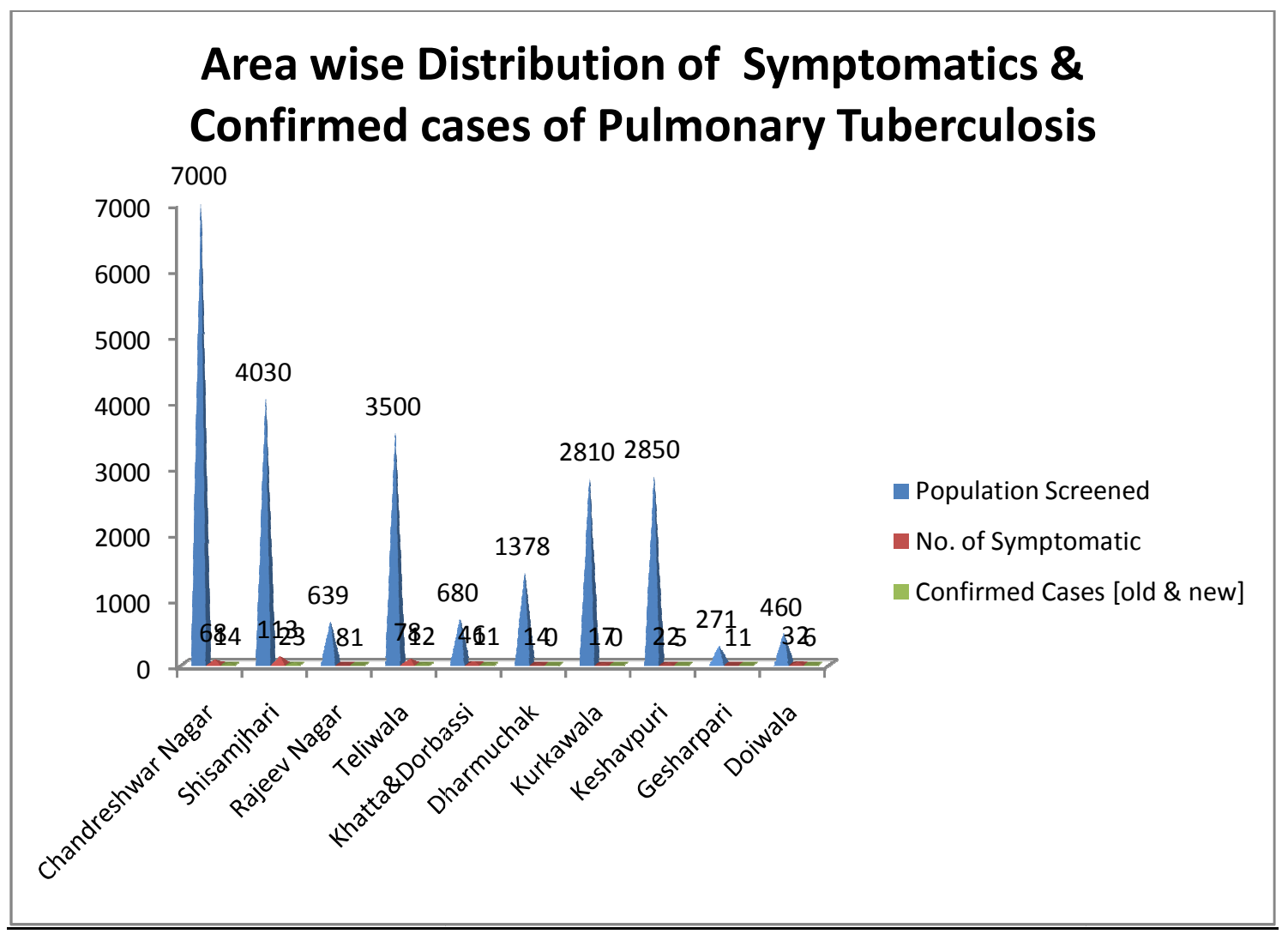

